This paper is a postprint of a paper submitted to and accepted for publication in Electric Power Systems Research and is subject to Elsevier Copyright. The copy of record is available at Science Direct:

http://www.sciencedirect.com/science/article/pii/S0378779611002707

L. M. R. Oliveira, A. J. M. Cardoso: "Application of Park's power components to the differential protection of three-phase transformers", Electric Power Systems Research, vol. 83, No. 1, pp. 203 - 211, February, 2012. 


\title{
Application of Park's Power Components to the Differential Protection of
}

\section{Three-Phase Transformers}

\author{
Luís M. R. Oliveira ${ }^{\mathrm{a}, \mathrm{b}, \mathrm{c},{ }^{*}}$ and A. J. Marques Cardoso ${ }^{\mathrm{a}, \mathrm{c}}$ \\ ${ }^{\text {a }}$ Department of Electrical and Computer Engineering, Faculty of Sciences and Technology, University of Coimbra, P- \\ 3030-290 Coimbra, Portugal \\ ${ }^{\mathrm{b}}$ High Institute of Engineering, University of Algarve, P-8005-139 Faro, Portugal \\ ${ }^{\mathrm{c}}$ Instituto de Telecomunicações, P-3030-290 Coimbra, Portugal
}

\begin{abstract}
This paper presents a new scheme for power transformers differential protection, in which the concept of the Park's instantaneous differential powers is introduced. The proposed method is able to detect winding insulation failures, and to distinguish them from magnetizing inrush current transients. Experimental and simulation results are presented and discussed.

Keywords: Differential protection, incipient winding faults, inrush currents, Park's vector, $p-q$ power theory, transformers.
\end{abstract}

\section{Introduction}

Power transformers are expensive components with high strategic importance in the power system network. Their reliable and continued performance is the key to profitable generation and transmission. Their costs of acquisition, replacement, transportation, installation and repairs are among the highest on the system [1]. Transformer failures are problematic because, while infrequent, they are potentially dangerous to utility personnel through explosions and fire, potentially damaging to the environment through oil leakage, are costly to repair or replace, and may result in significant loss of revenue [2]. The capital loss of an accidental power transformer outage is often counted in million dollars for output loss only, not to say the costs associated with repair or replacement [3]. When a transformer fault occurs, it must be cleared as soon as possible in order to minimize the consequential damage. Accordingly, the correct operation of the power transformer

\footnotetext{
* Corresponding author. Tel.: +351 289800100; fax: +351 289888405.

E-mail addresses: lolivei@ualg.pt (L. M. R. Oliveira), ajmcardoso@ieee.org (A. J. M. Cardoso)
} 
protection systems is of critical importance to the power system reliability.

The differential protection scheme is the most widely accepted method for the protection of transformers of 10 MVA and above. The transformer primary- and secondary-side currents are compared: if a disproportional relation is detected a fault is assumed and the transformer is disconnected.

One of the major concerns in power transformer differential protection is to avoid the relay false trip during an inrush transient. It has long been known that transient magnetizing inrush currents, sometimes reaching magnitudes as high as 8-12 times fullload current, may flow in a transformer winding for a period following the moment when it is energized by connecting it to an electric power circuit [4]. Since magnetizing inrush currents flow in the transformer primary windings only, the differential relays may respond as for transformer internal faults, thereby tripping the breakers immediately after they have been closed [5].

Proposed more than 70 years ago [6], the harmonic current restrained principle is commonly used to discriminate between switching-on transients and internal faults. Typically, the second harmonic is a major component of the inrush current. In contrast, the fault harmonics are generally small. Thus, in principle, the second harmonic provides an effective means to distinguish between faults and inrush [7]. However, the $2^{\text {nd }}$ harmonic component may also be generated during internal faults in the transformer, with relevant magnitudes. Moreover, advancements made to transformer technology in the past three decades have changed the characteristics of the transformer inrush current (peak, $2^{\text {nd }}$ harmonic and duration), due to the use of higher grain oriented core steels, the step-lap core joint type, and higher rated design core induction values $[8,9]$. In modern power transformers, the $2^{\text {nd }}$ harmonic during inrush may be very low, jeopardizing relay security [10]. 
Usually, the harmonic components of the differential currents are computed by using the Discrete Fourier Transform (DFT). As power system disturbances are subject to transient and non-periodic components, the DFT alone can be an inadequate technique for signal analysis [11]. In addition to the previous mentioned drawbacks, this could be another factor that contributes to reduce the security of the traditional $2^{\text {nd }}$ harmonic restrained differential relays.

Moreover, in the case of turn-to-turn insulation faults, even though the currents at the fault location may possibly be very high and dangerous, the differential currents are relatively small [12]. The traditional transformer differential protection is typically not sensitive enough to detect such winding defects before they have developed into more serious and costly to repair ground-faults [13].

As it is evident from the preceding paragraphs, it is of prime importance the development of protection schemes, which can improve the sensitivity of differential relays to detect incipient winding faults and which can also provide a solution to the second harmonic restrain drawbacks. Not surprisingly, a significant amount of research work has been devoted over the last decades to solve the inrush/fault discrimination dilemma of the transformer differential protection. Several solutions have been proposed in this context, including the refinement of the traditional harmonic restrain methods [1417], the development and exploration of new trip and restrain signals [10, 12-13, 18-31], the use of wave-shape recognition methods [32-34], and the application of advanced digital signal processing tools [11, 35-37], fuzzy logic and artificial intelligence techniques $[31,38-40]$. These methods can provide an alternative or improvement to the existing protective relaying functions. However, no new method seems to have reached a practical level yet, and the second harmonic component-based scheme has to be widely used, regardless of its shortcomings [22]. Therefore, it seems that significant scope of 
research for prompt and more reliable techniques on power transformer protection exists [40].

The active power differential method was firstly proposed in [23] for the discrimination between inrush transients and internal faults in power transformers. The differential power is computed as the difference between the instantaneous powers at all the transformer's terminals. In [23], the average of the instantaneous differential power is responsible for both the operation and the blocking signals of the relay. The discrimination criterion is based on the following basic principle: the average power is almost zero for energizing, but an internal fault consumes large power. However, the direct application of the average power as a decision signal for the discrimination of inrush/fault conditions can lead to misleading results, due to the oscillations of the average active power, as reported in $[23,28]$.

More recently, the active power differential method has received considerable research attention and some developments to the initial approach have been reported. The method proposed in [29] computes the active differential power from the differential currents and virtual differential voltages. In [28], a combined power-current spectrum blocking technique was presented. The use of the instantaneous frequency of the average active differential power to discriminate between internal faults and inrush transients was proposed in [30]. In [31] the active power differential method is used in conjunction with a probabilistic neural network. In all these studies the transformer switching transient is identified by using the active power. However, the inrush current is a primarily reactive phenomenon, and the most natural power-related quantity that characterizes the magnetic energy variation during the inrush transient is the reactive power. Furthermore, a straightforward method to compute the active and reactive instantaneous powers in threephase systems is provided by the application of the $p-q$ power theory [41] (or Park's power 
components). In this way, the application of the $p$ - $q$ theory to the power differential method is particularly attractive, since the active power component is directly related with the internal fault within the transformer and the reactive power component is associated with the inrush transient.

This work explores the possibility of applying the Park's power components to solve the inrush/fault discrimination dilemma in power transformers differential protection. With this approach, the traditional $2^{\text {nd }}$ harmonic restrain shortcomings are avoided. Moreover, the harmonic components computation is not required and the DFT inherent limitations are overcome. The proposed protection strategy is computationally inexpensive, since it only requires a sliding-window arithmetic average of the differential active and reactive power signals.

Additionally, the error introduced by the current mismatch due to the tap-changer is minimized, and increased sensitivity is obtained in the differential protection system.

\section{Experimental setup and computer simulation models}

For the experimental investigation a three-phase, two winding, three leg transformer, of $10.3 \mathrm{kVA}, 230 / 132 \mathrm{~V}$, was used. The primary and the secondary windings have 152 and 90 turns, respectively. In each winding of the transformer there are five additional tappings connected to the coils, allowing for the introduction of shorted turns at several locations in the winding, as shown in Fig. 1(a), for the phase $R$ of the transformer high voltage winding.

For the experimental analysis of the switching-on transients, the point of the voltage waveform at which the transformer is energized is controlled by using electronic switches in a custom-built power electronics board. Before each switching action the transformer core is demagnetized.

The faults are introduced in the test transformer by connecting a shorting resistor $\left(R_{s h}\right)$ 
at the terminals of the affected turns. The value of this resistor was chosen so as to create an effect strong enough to be easily visualized, but simultaneously big enough to limit the short-circuit current and thus protect the test transformer from complete failure when the short is introduced. The instant at which the fault occurs is adjusted by another power electronics board, similar to the one used to study the transformer energization transients.

The experimental study of winding inter-turn short-circuits occurrence presents some inherent difficulties: the current in the shorted turns must be limited to the rated current of the winding and the fault location is established by the tappings position. Therefore, a detailed analysis of these phenomena can be better investigated by the additional use of a suitable digital simulation transformer model. For that purpose, a coupled electromagnetic transformer model was developed [42], which is based on the combination of both magnetic and electric lumped parameters equivalent circuits. A detailed description of the model implementation and validation can be found in [42].

The results presented in this paper refer to a Dyn5 transformer winding connection, Fig. 1(b). The transformer was energized by the high-voltage side and the supply and line equivalent impedances were taken into account in the simulation study [Fig. 1(b)]. In a similar manner to that presented in [43], the differential currents $\left(i_{d 1}, i_{d 2}\right.$ and $\left.i_{d 3}\right)$, for the Dyn5 winding connection, are computed as follows:

$$
\left[\begin{array}{l}
i_{d 1} \\
i_{d 2} \\
i_{d 3}
\end{array}\right]=\left[\begin{array}{l}
i_{L 1} \\
i_{L 2} \\
i_{L 3}
\end{array}\right]+\frac{N_{S}}{N_{p}} \cdot\left[\begin{array}{rrr}
1 & 0 & -1 \\
-1 & 1 & 0 \\
0 & -1 & 1
\end{array}\right]\left[\begin{array}{l}
i_{L 4} \\
i_{L 5} \\
i_{L 6}
\end{array}\right]
$$

where $N_{p}$ and $N_{s}$ are the number of the primary and secondary turns, respectively.

The instrumentation system basically comprises a personal computer, a data acquisition board, a current measurement system based on Hall-effect current sensors, and a voltage measurement device with isolation amplifiers. A $5 \mathrm{kHz}$ sampling frequency was 
used for the digital acquisition of the current and voltage signals.

\section{Protection strategy based on the Park's power components}

The application of the space vector theory to the differential protection and/or on-line condition monitoring of power transformers has been recently reported in the literature [24-27, 44]. The Park's power components technique has also been successfully used to diagnose AC motor faults $[45,46]$. To the author's knowledge, however, it has not been previously proposed any transformer protection scheme which takes advantage of the combination of the power differential method and the Park's power components. The methodology for the computation of the instantaneous active and reactive differential powers is presented in the following subsection.

\subsection{Differential power components computation}

A two-winding transformer with a DYn5 winding connection [Fig. 1(b)] is considered here, but the method is valid for any multi-winding transformer. For simplicity, the differential power components are computed using phase quantities. The phase currents of the delta-connected winding can be computed from the line (measured) currents by:

$$
\left[\begin{array}{l}
i_{R} \\
i_{S} \\
i_{T}
\end{array}\right]=\frac{1}{3}\left[\begin{array}{rrr}
1 & -1 & 0 \\
0 & 1 & -1 \\
-1 & 0 & 1
\end{array}\right] \cdot\left[\begin{array}{l}
i_{L 1} \\
i_{L 2} \\
i_{L 3}
\end{array}\right]
$$

By applying (2) the zero-sequence component of the phase currents is neglected. This is not detrimental to the method implementation, since the zero-sequence current must be eliminated from the differential scheme, in order to avoid relay mal-operation in the case of an external fault [7]. Moreover, all the zero-sequence components are eliminated when the $p-q$ power components are computed.

The d-q components of the voltage and current, of high and low voltage sides of the transformer, are computed by applying the Park's transformation. The Park's vector 
components are:

$$
\begin{gathered}
{\left[\begin{array}{ll}
v_{D 1} & v_{Q 1}
\end{array}\right]^{T}=T \cdot\left[\begin{array}{lll}
v_{R S} & v_{S T} & v_{T R}
\end{array}\right]^{T}} \\
{\left[\begin{array}{ll}
v_{D 2} & v_{Q 2}
\end{array}\right]^{T}=T \cdot\left[\begin{array}{lll}
v_{r n} & v_{s n} & v_{t n}
\end{array}\right]^{T}} \\
{\left[\begin{array}{ll}
i_{D 1} & i_{Q 1}
\end{array}\right]^{T}=T \cdot\left[\begin{array}{lll}
i_{R} & i_{S} & i_{T}
\end{array}\right]^{T}} \\
{\left[\begin{array}{ll}
i_{D 2} & i_{Q 2}
\end{array}\right]^{T}=T \cdot\left[\begin{array}{lll}
i_{r} & i_{s} & i_{t}
\end{array}\right]^{T}}
\end{gathered}
$$

where $T$ is the Park's transformation matrix:

$$
T=\left[\begin{array}{ccc}
\frac{\sqrt{2}}{\sqrt{3}} & \frac{-1}{\sqrt{6}} & \frac{-1}{\sqrt{6}} \\
0 & \frac{1}{\sqrt{2}} & \frac{-1}{\sqrt{2}}
\end{array}\right]
$$

Then, the primary and secondary side Park's power components are computed:

$$
\begin{aligned}
& p_{k}=v_{D k} \cdot i_{D k}+v_{Q k} \cdot i_{Q k}, \quad k=1,2 \\
& q_{k}=v_{Q k} \cdot i_{D k}-v_{D k} \cdot i_{Q k}, k=1,2
\end{aligned}
$$

and finally the differential active and reactive power components are:

$$
\begin{gathered}
p_{d(\text { with copper losses })}=p_{1}-p_{2} \\
q_{d(\text { load dependent })}=q_{1}-q_{2}
\end{gathered}
$$

As stated before, the occurrence of an internal fault leads to an increment of the consumed active power. The winding copper losses can be subtracted in (10), increasing the sensitivity of the differential active power to detect winding faults. With this refinement, the differential active power is equal to the no-load and stray losses, under normal operation. The modified differential active power is given by:

$$
p_{d}=p_{1}-p_{2}-\left[R_{1} \cdot\left(i_{D 1}^{2}+i_{Q 1}^{2}\right)+R_{2} \cdot\left(i_{D 2}^{2}+i_{Q 2}^{2}\right)\right]
$$

where $R_{1}$ and $R_{2}$ are the primary- and secondary-side winding resistances, respectively.

Increased sensitivity can be further achieved by subtracting the no-load losses in (12) or even by taken into consideration the windings resistance variation with the windings 
temperature. These factors are not considered here.

The instantaneous differential reactive power in (11) depends on the transformer load, since it includes the reactive power supplied to the short-circuit reactance. This dependence can also be minimized, by deducting in (11) the contribution of the leakage inductances:

$$
q_{d}=q_{1}-q_{2}-\left[L_{1} \cdot\left(\frac{d i_{Q 1}}{d t} i_{D 1}-\frac{d i_{D 1}}{d t} i_{Q 1}\right)+L_{2} \cdot\left(\frac{d i_{Q 2}}{d t} i_{D 2}-\frac{d i_{D 2}}{d t} i_{Q 2}\right)\right]
$$

where $L_{1}$ and $L_{2}$ are the primary- and secondary-side leakage inductances, respectively.

\subsection{Differential power signature during an incipient fault}

The severity of the fault depends not only on the number of shorted turns, but also on the value of the fault current, which is limited by the fault impedance [44]. The fault is introduced in the primary winding of phase $R$, and the turns are shorted through the auxiliary resistor.

\subsubsection{Incipient fault without overcurrent}

The transformer was tested under $20 \%$ rated load (balanced resistive load) and the fault is introduced at $t=40 \mathrm{~ms}$, when the voltage across the taps $U_{B}-U_{D}$ [four shorted turns, Fig. 1(a)] begins the positive half-cycle.

The auxiliary resistor was adjusted to approximately $0.35 \Omega$, so that the current in the shorted turns is limited to the rated value of the current in the affected winding $\left(I_{\text {short }} \approx\right.$

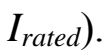

The occurrence of primary-side interturn short-circuits leads to an increment in the magnitude of the current in the affected winding, as compared to a healthy condition. Due to the delta connection of the primary winding, the increment in the current of the faulty phase affects two line currents [since $i_{L 1}=i_{R}-i_{T}$ and $i_{L 2}=i_{S}-i_{R}$; notation as per Fig. 1(b)]. Accordingly, the corresponding differential currents are also affected, as shown in 
Fig. 1(c). It can be seen that these differential currents increase almost instantaneously when the fault is introduced, maintaining a nearly symmetrical waveform.

(a)
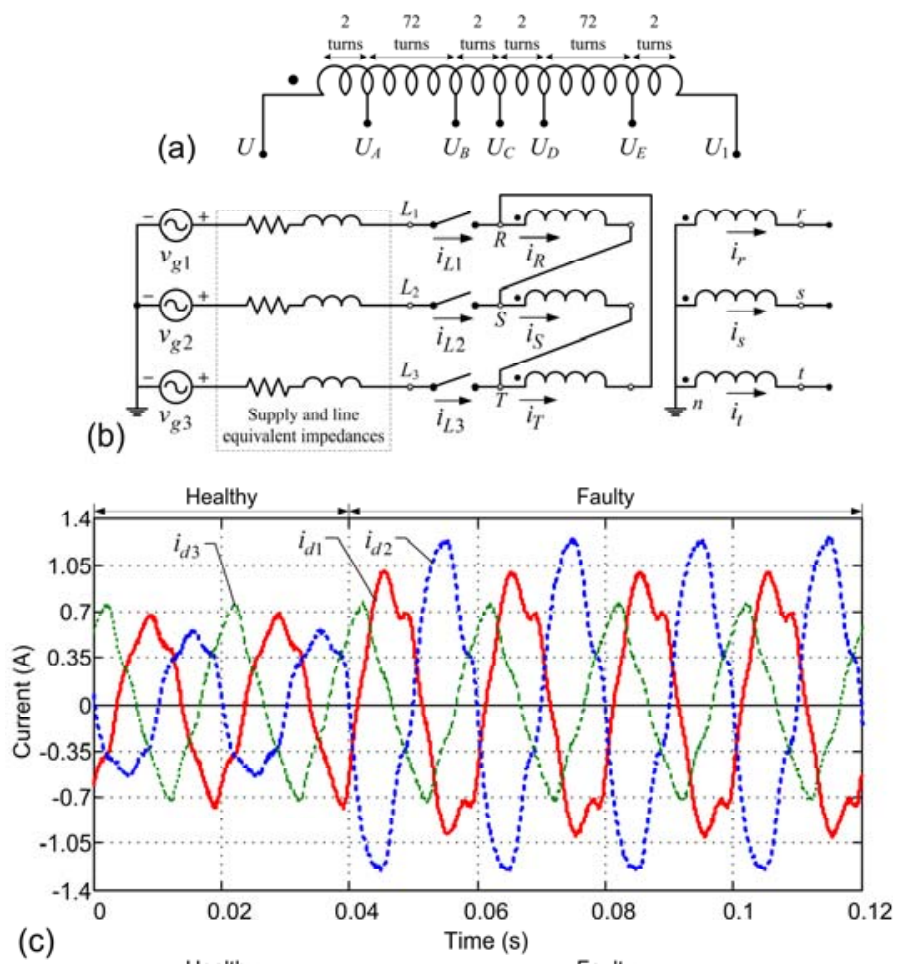

(c)

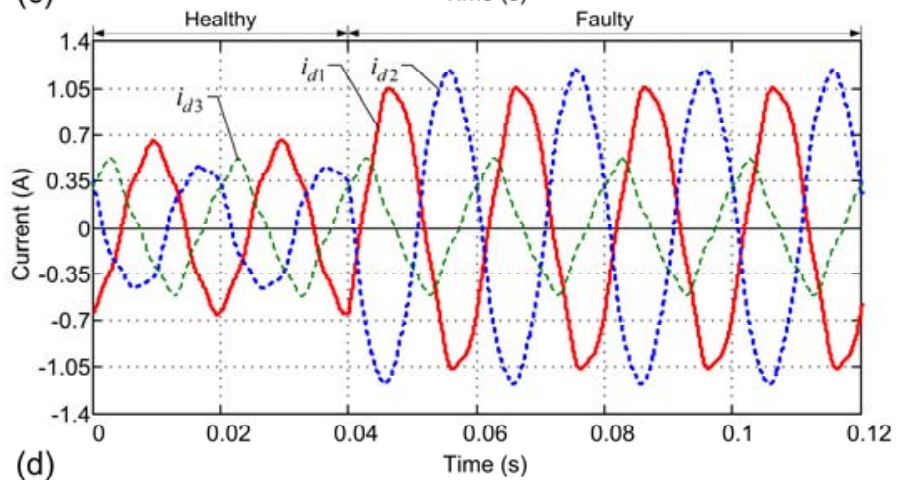

(d)

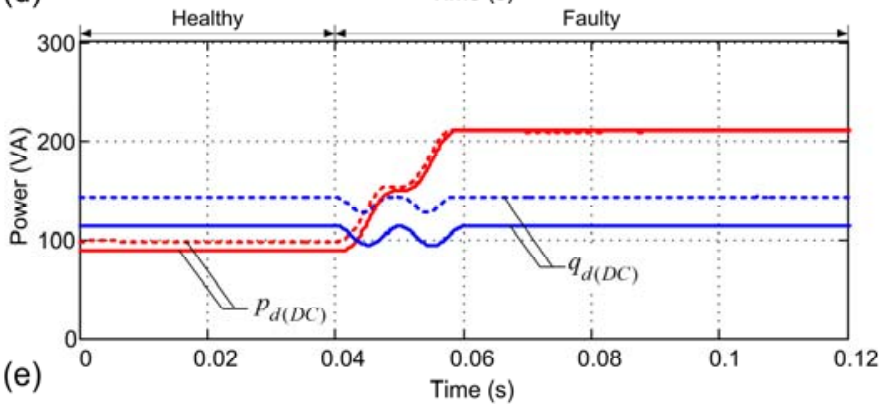

Fig. 1. (a) Location of the tappings for transformer primary winding (phase $R$ ); (b) schematic of the experimental setup. Turn-to-turn winding fault transient without overcurrent: differential current waveforms [(c) experimental; (d) simulated]; (e) moving average of the differential power components, dashed: experimental; solid: simulated (test conditions: 4 shorted turns in the primary winding of phase $R, R_{s h} \approx 350$ $\mathrm{m} \Omega, I_{\text {short }} \approx I_{\text {rated }}$ and $20 \%$ of full load). 
The increase in the magnitude of the differential currents, due to an incipient insulation defect, with only a few turns involved, is small, even if the fault current is large. This applies, in particular, to the present case, where none of the rated parameters of the test transformer are exceed, and it is very likely that the fault remains undetected by the protection devices, until it progresses to a major failure.

Fig. 1(d) presents the corresponding simulation results. The recorded and the computed signals are in a very good agreement.

\subsubsection{Incipient fault with overcurrent}

The analysis of the transformer behavior under the occurrence of more severe turn-toturn faults cannot be carried out experimentally, due to the physical limitations of the test transformer. Using the digital simulation model a more severe fault was analyzed, with six shorted turns and a fault current of approximately five times the rated current of the primary winding.

The harmonic content of the differential currents was calculated using a Discrete Fourier Transform with a moving window. Fig. 2(a) presents the evolution of the DC, fundamental and second harmonic components of the differential current $i_{d 1}$ during the fault occurrence. After the fast current rise, the DC and the $2^{\text {nd }}$ harmonic components are negligible, and only the fundamental component is affected by the occurrence of the fault. For the case of the moderate fault ( 6 shorted turns, $\left.I_{\text {short }} \approx 5 \times I_{\text {rated }}\right)$, the fundamental component increases about eight times when the fault occurs [Fig. 2(a)] and this differential signal reaches up to $15 \%$ of the power transformer primary-side rated current. This is in the range of the minimum differential protection pickup (e.g. 15\%-20\%) typically required for the operation of the relay. Therefore, it can be assumed that this fault would be the smallest interturn insulation defect that can be detected by the traditional 
protection systems.

It should be noted, however, that a higher value of the minimum protection pickup setting is often used, in order to deal with the ratio and phase mismatches and avoid false trips of the protection system. In this case the turn-to-turn fault of Fig. 2(a) may not be detectable initially and the winding protection is uncertain.

The main reason of high percent-unprotected windings is due to the tap changing of the transformer [47]. The variation of the actual transformer turns ratio by means of a tap changer introduces an error in the computation of the differential currents [as in (1)]. The relay percentage restraint and minimum operating settings are configured to accommodate the ratio mismatch [48], reducing the fault detection sensitivity of the protection system.

Fig. 2(b) presents the evolution of the differential power components during a turn-toturn winding fault occurrence. Under healthy conditions the instantaneous differential power components present some oscillations, which differ from the constant value expected for an ideal situation, due to, among others, the nonlinear behavior and asymmetry of the magnetic circuit.

After fault inception there is an increase in the magnitude of both instantaneous power components $\left(p_{d}\right.$ and $\left.q_{d}\right)$. A further insight into the characteristics of the differential power components can be obtained by the analysis of the moving averages of the power signals. These were computed by using a sliding-window arithmetic average, over one cycle of the line frequency. For the $i$-th sample, the average of the instantaneous powers over the last cycle is given by:

$$
\begin{aligned}
& p_{d(D C)}(i)=\left|\frac{1}{n} \sum_{j=i-n+1}^{i} p_{d}(j)\right| \\
& q_{d(D C)}(i)=\left|\frac{1}{n} \sum_{j=i-n+1}^{i} q_{d}(j)\right|
\end{aligned}
$$


where $n$ is the number of samples per cycle.

The average powers can take negative values [23], due to the distortion of the current and voltage waveforms or due to the existence of bidirectional power flow in a looped network. For that reason the absolute value of the average powers is considered in (14) and (15).

The corresponding results are presented in Fig. 2(c). It can be seen that the average value of the active power $\left(p_{d(D C)}\right)$ is substantially affected by the presence of the fault. The average value of the active power increases about 10 times as a result of the winding fault occurrence, which results in only a slightly improvement of the fault detection sensitivity, as compared to the fundamental component of the line currents involved with the affected phase (which increases 8 times for the same type of fault, as seen before). However, the differential power method is not affected by the ratio mismatch due to on-load tapchanger, and enhanced fault detection sensitivity is thus achieved. Therefore, the average value of the differential active power is a reliable indicator of the presence of a fault, and can be used as a trip signal of the differential relay.

To detect this low-level turn-to-turn fault the trip signal should be activated when $p_{d(D C)}$ exceeds a threshold of $800 \mathrm{~W}$. This is about 10 times the normal operating value (which is equal to the no-load losses). This allows the power differential relay to accommodate the measurement errors without nuisance tripping and still providing reliable fault detection.

Although the instantaneous value of the reactive power component is also affected by the fault occurrence, the variation of its average value $\left(q_{d(D C)}\right)$ is small, as shown in Fig. 2(c). The discrimination between the healthy and the faulty condition of the transformer is thus fully characterized by the combined behavior of the two average Park's power components. A relation between these two quantities can be obtained by computing their 
ratio $\left(q_{d(D C)} / p_{d(D C)}\right)$. After the fault occurrence this ratio decreases, Fig. 2(d), and does not provide any relevant information about interturn short-circuits that may occur. However, it plays a very important role for discriminating between inrush and fault conditions, as explained in the next section.
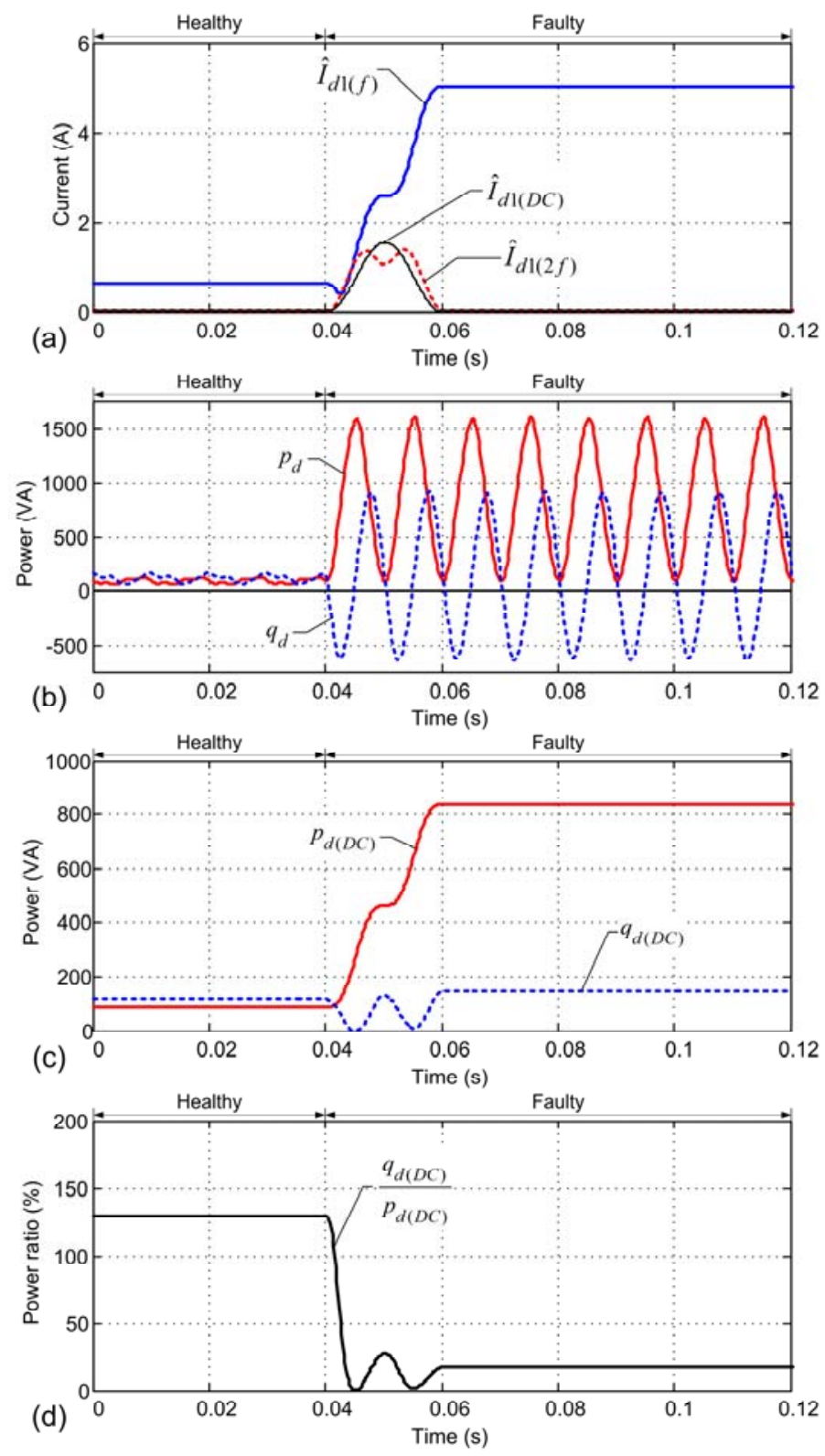

Fig. 2. Turn-to-turn winding fault transient with overcurrent: (a) DC, fundamental and second harmonic components of the differential current $i_{d 1}$; (b) instantaneous differential power components; (c) moving averages of the differential power components; (d) power ratio $q_{d(D C)} / p_{d(D C)}$ (simulated results; test conditions: 6 shorted turns in the primary winding of phase $R, R_{\text {sh }} \approx 94 \mathrm{~m} \Omega, I_{\text {short }} \approx 5 \times I_{\text {rated }}$ and $20 \%$ of full load). 
For the case of the incipient fault without overcurrent $\left(I_{\text {short }} \approx I_{\text {rated }}\right)$, both experimental and simulated results of $q_{d(D C)}$ and $p_{d(D C)}$ are presented in Fig. 1(e), which are in relatively good agreement.

\subsection{Differential power signature during inrush current}

The transformer terminals were connected simultaneously to the supply when the voltage between line $1\left(L_{1}\right)$ and line $2\left(L_{2}\right)$ is starting its positive half-cycle [notation as per Fig. 1(b)]. The transformer was switched-on under no-load condition, and, thus the relay differential currents in (1) are equal to the primary-side line currents $\left(i_{d 1}=i_{L 1}, i_{d 2}=i_{L 2}\right.$ and $\left.i_{d 3}=i_{L 3}\right)$. The transformer energization occurs at $t=20 \mathrm{~ms}$.

Typical inrush current waveforms were obtained. Fig. 3(a) presents the waveforms of the instantaneous experimental inrush currents. In this case the transient is strongly attenuated after $200 \mathrm{~ms}$, but may last tens of seconds or even a few minutes in the case of large power transformers [49]. Fig. 3(b) presents the corresponding simulated results, which are in good agreement with the experimental ones.

Fig. 3(c) presents the evolution of the DC, the fundamental and the $2^{\text {nd }}$ harmonic components of the current in line 1 during the energization of the transformer. If not correctly restrained, a spurious trip of the relay will occur, due to the high value of the line current fundamental component.

The evolution of the ratio of the $2^{\text {nd }}$ harmonic to the fundamental of the inrush currents $\left(\hat{I}_{L(2 f)} / \hat{I}_{L(f)}\right)$ is presented in Fig. 3(d). The operation of the differential relay is usually blocked if this ratio is larger than $15 \%-20 \%$ [15]. Assuming a restraint ratio of $20 \%$, it can be seen from Fig. 3(d) that the transformer protection is inhibited during a time interval of about $0.95 \mathrm{~s}$ to $1.25 \mathrm{~s}$, approximately, depending on the line current under consideration and/or the method used for harmonic blocking [15]. For this particular test the traditional $2^{\text {nd }}$ harmonic restrain method properly blocks the differential element. 
However, this is not always the case, and the amount of the $2^{\text {nd }}$ harmonic may drop considerably in modern power transformers, as mentioned before, which may cause malfunction of the relay.

The evolution of $p_{d}$ and $q_{d}$ during the transformer inrush transient is shown in Fig. 4(a). The reactive component is largely affected during the energization of the transformer, in order to supply the magnetic energy to be stored in the windings. Comparatively, the instantaneous active power is much smaller. Moreover, its average value $\left(p_{d(D C)}\right)$ has a reduced variation, as compared to $q_{d(D C)}$, as seen in Fig. $4(\mathrm{~b})$. The oscillations in the average active power are relatively small and $p_{d(D C)}$ rapidly reaches the reference value for healthy operating conditions $(\approx 100 \mathrm{~W})$. On the contrary, the average reactive power takes high values at the beginning of the energization transient, falling then slowly, with the same rate as the inrush currents, to the steady-state value. These are the two key characteristics of the Park's power components during an inrush transient, and their behavior is exactly the opposite to that it was observed when a fault occurs.

The power ratio $q_{d(D C)} / p_{d(D C)}$ combines these two characteristics. The transformer energization can be detected by using this ratio, as seen in Fig. 4(c), blocking the relay operation if $q_{d(D C)} / p_{d(D C)}$ is above a predefined threshold value.

For the present case the threshold value of the restraint ratio can be assumed to be $400 \%$. In general, the normal operating value for $q_{d(D C)} / p_{d(D C)}$ can be obtained by using the no-load test data, $Q_{\text {no-load }} / P_{\text {no-load. }}$ A safety margin is introduced between the threshold and the normal operation status, to avoid blocking the relay trip signal under the simultaneous occurrence of inrush currents and internal faults. It is considered here that the threshold is about 3 times the normal operating value.

The resultant restraint signal is shown in Fig. 4(d), which inhibits the relay during the energization transient. 

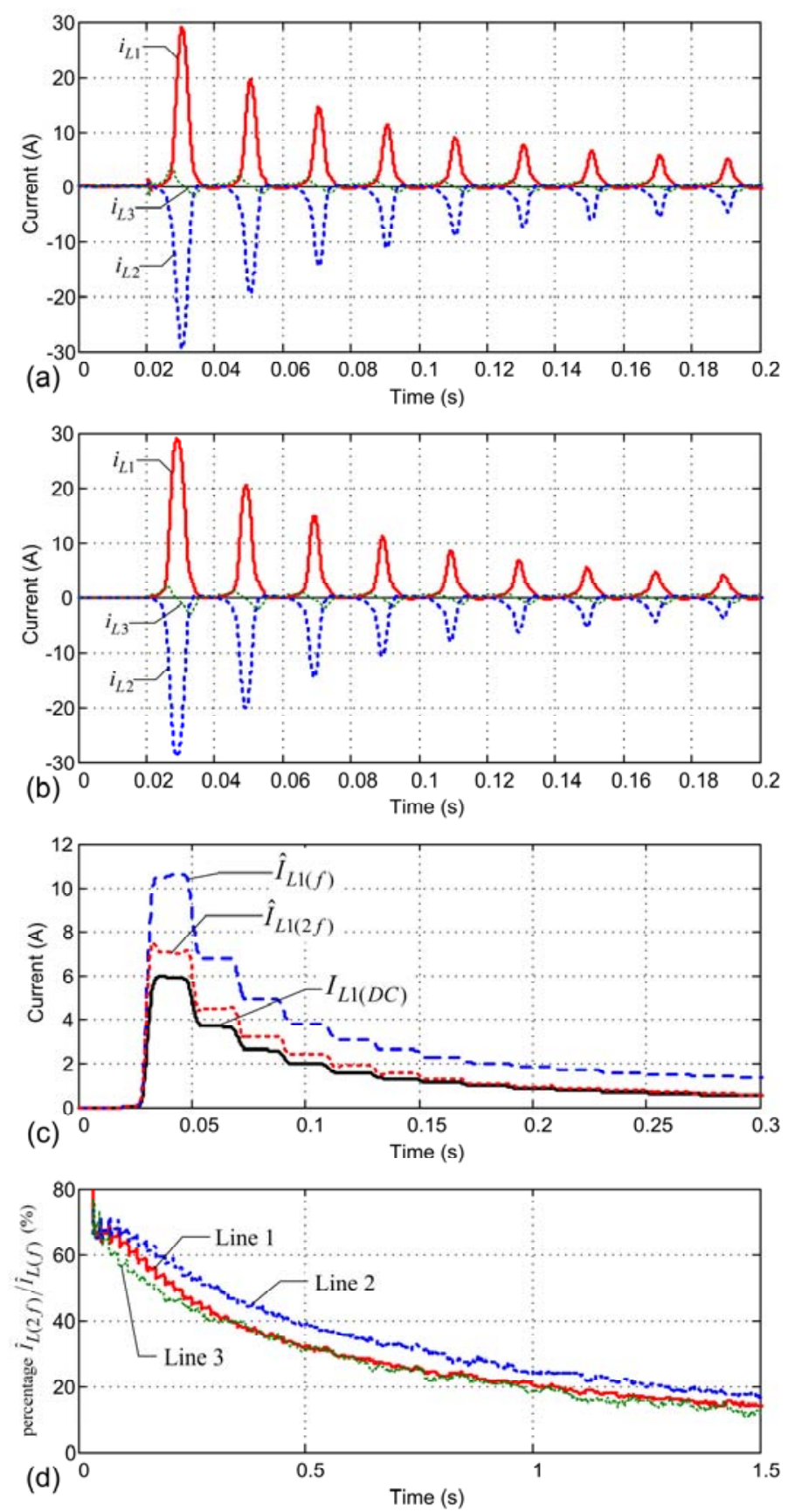

Fig. 3. Transformer energization transient. Evolution of the line current waveforms: (a) experimental results; (b) simulated results. (c) Evolution of the harmonic components of $i_{L 1}$ (experimental results). (d) Evolution of the ratios of the $2^{\text {nd }}$ harmonic to the fundamental of the line currents (experimental results). (Test conditions: no-load; transformer switched-on at $t=20 \mathrm{~ms}$.)

It should be noted that there are cases where the average active power presents oscillations with significant magnitude at the beginning of the inrush transient. It is difficult in these conditions to distinguish the switching inrush from fault conditions [23] 
when monitoring the $p_{d(D C)}$ signal alone. These limitations are overcome when both the active and reactive powers are used as discrimination criteria.
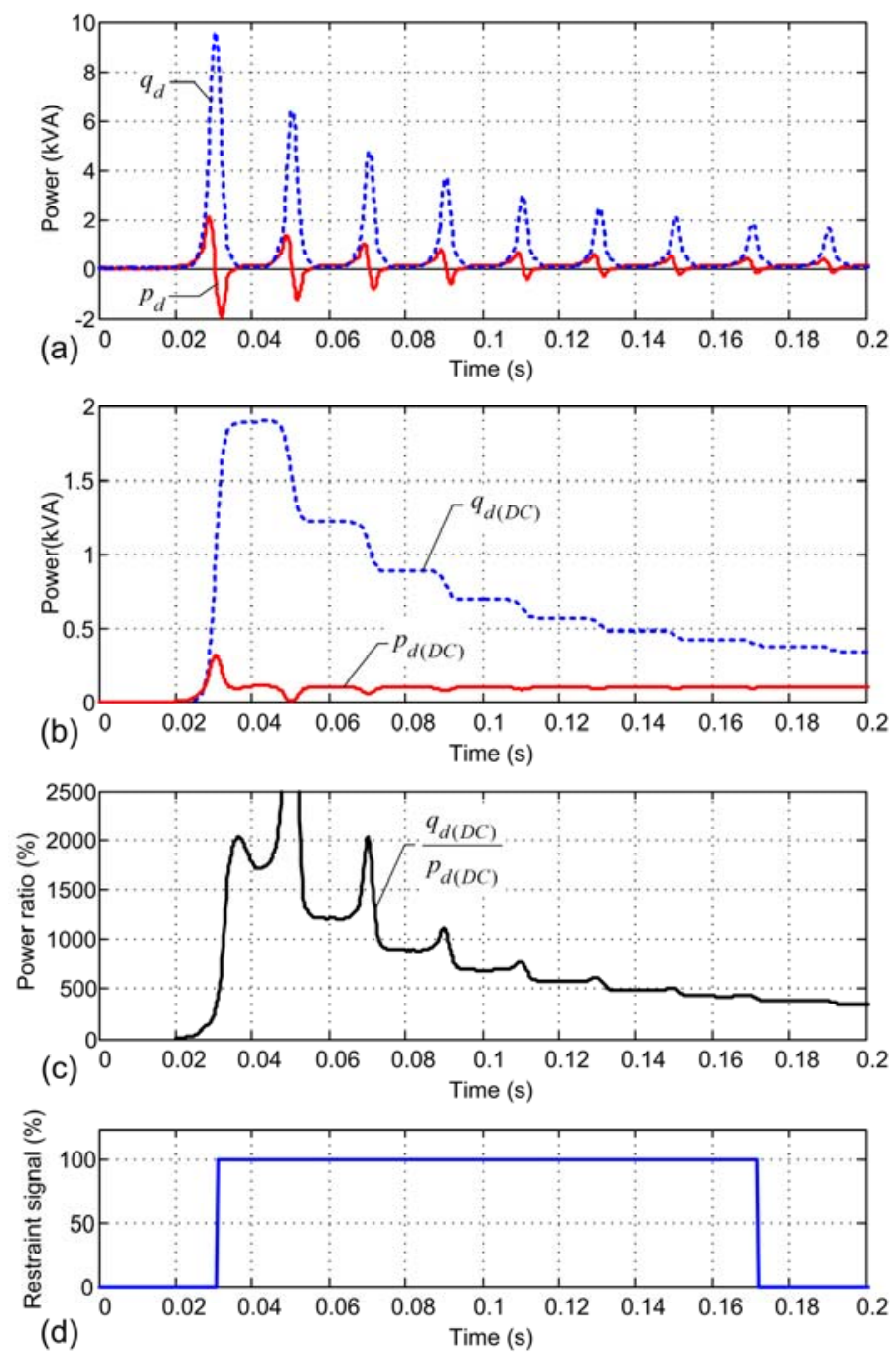

Fig. 4. Transformer energization transient: (a) instantaneous differential power components; (b) moving averages of the power differential components; (c) power ratio $q_{d(D C)} / p_{d(D C)}$; (d) restraint signal: when equal to $100 \%$ the relay is blocked (experimental results; same conditions as in Fig. 3). 


\subsection{Differential power signature during a simultaneous occurrence of fault and inrush}

current

Fig. 5(a) shows the evolution of the per-phase $2^{\text {nd }}$ harmonic ratios for all the three phases when the transformer is energized, with the same conditions of section 3.3 , but with six shorted turns in phase $R$, with $I_{\text {short }} \approx 5 \times I_{\text {rated }}$. As a consequence of the fault, this ratio decays faster in the two line currents involved with the damaged phase, as compared to a healthy condition. Even so, the operation of the relay is delayed: if a per-phase blocking scheme is used, the protection in the affected lines is blocked during $150 \mathrm{~ms}$, approximately. However, if a three-phase cross-blocking method is employed, the tripping signal is inhibited during approximately the same time as in the healthy inrush $(0.75 \mathrm{~s})$, and the transformer protection is uncertain.

The corresponding instantaneous power components waveforms are presented in Fig. 5(b). They can be considered, roughly, as the sum of the individual transient contributions of the fault and inrush characteristics [Figs. 2(b) and 4(a), respectively]. Obviously, the differential power components are dominated, during the first cycles, by the energization transient, due to the relatively larger values of the inrush power signals.

The average reactive power is substantially affected during the faulty energization of the transformer, Fig. 5(c), in a similar manner to the healthy inrush, since the fault occurrence has a reduced effect on $q_{d(D C)}$. On the contrary, the inrush does not noticeably affects the average active power, but the faulty condition of the transformer does, resulting in a considerable increase of $p_{d(D C)}$, Fig. 5(c), as compared to a healthy energization transient. The average active power rapidly grows, with a few small oscillations, to the steady state value obtained when the switching-on transient is not present $[\approx 800 \mathrm{~W}$, Fig. 2(c)]. The trip signal is activated almost immediately after the faulted transformer is energized. 
The evolution of the power ratio $q_{d(D C)} / p_{d(D C)}$ is presented in Fig. 5(d). It can be seen that the threshold value of the restraint ratio (400\%) is not reached and the trip signal, which is rapidly triggered by the large value of the average active power, is not blocked. With the differential power signature approach the delayed operation of the relay, that usually occurs with the traditional $2^{\text {nd }}$ harmonic restrain method, is avoided.
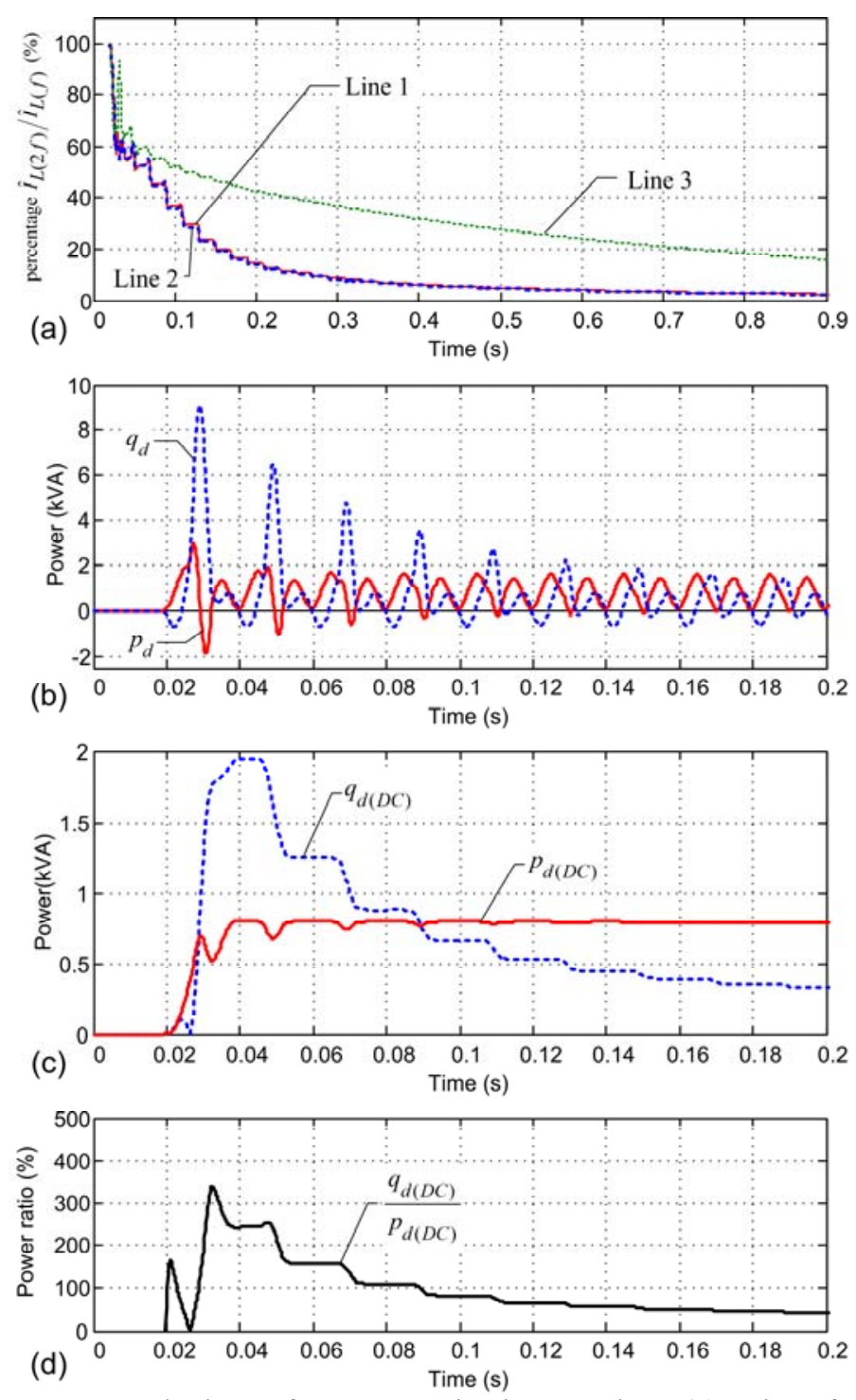

Fig. 5. Faulted transformer energization transient: (a) ratios of the $2^{\text {nd }}$ harmonic to the fundamental of the line currents; (b) evolution of $q_{d}$ and $p_{d}$; (c) evolution of $q_{d(D C)}$ and $p_{d(D C)}$; (d) evolution of the power ratio $q_{d(D C)} / p_{d(D C)}$ (simulated results; test conditions: no-load; transformer switched-on at $t=20 \mathrm{~ms} ; 6$ shorted turns in the phase $R$ of the primary winding; $I_{\text {short }} \approx 5 \times I_{\text {rated }}$ ). 


\subsection{Internal/external fault discrimination with the differential power signature}

External fault current when combined with ratio mismatch may generate a false differential signal in the traditional differential relays [10]. Fig. 6 presents the results for the case of an external fault occurrence, at $t=40 \mathrm{~ms}$, followed by an interturn winding fault of the transformer, at $t=120 \mathrm{~ms}$. Initially the power transformer is under steady-state full-load conditions. The external fault consists of a single-phase, line-to-ground fault, on the secondary-side of the transformer (phase $r$ ), resulting in a current $I_{r} \approx 5 \times I_{r(\text { rated }) \text {. The }}$ internal fault characteristics are identical to the ones in subsection 3.2.2. For the case presented in Fig. 6 it is assumed that the current transformers (CT's) reproduce the primary currents correctly.

Fig. 6(a) presents the evolution of the fundamental component of the differential current $i_{d 1}$. The influence of the ratio mismatch due to the tap-changer operation is analyzed. If no ratio mismatch exists the differential current is not affected by the external fault and correctly detects the internal fault (curve labeled "no ratio error"). However, if an error of $+/-10 \%$ is introduced in the computation of the differential currents in (1), the external/internal fault discrimination is no longer possible.

The evolution of the instantaneous active power changes abruptly when the external fault occurs, Fig. 6(b). However, their average value remains approximately constant and the relay operation remains stable, Fig, 6(c). As well, the external fault has irrelevant effects on the average reactive power. After the internal fault occurrence the overall behavior of the active and reactive powers is identical to the ones presented in Fig. 2, and the power differential relay operates correctly, tripping the transformer. The power differential technique is not affected by the operation of the tap-changer because a change in the tap position proportionately affects the voltages and currents magnitudes. 
Fig. 7 presents the same case of Fig. 6, but considering now the occurrence of CT's saturation. Fig 7(a) presents the distorted secondary-side currents of the saturated CT's, referred to the primary-side (the subscript $C T$ is used in the CT's secondary-side currents). As a consequence of these distorted signals a high differential current will result, Fig. 7(b), which would cause the relay to trip if there is no stabilization against the CT saturation phenomena.

Similarly to what happens with traditional protection systems, the saturation of current transformers adversely affects the performance of the proposed protection strategy. The effect of the CT saturation in the active and reactive power components is shown in Figs 7(c) and (7(d). Obviously, the discrimination between internal and external faults is no longer possible when CT saturation is present.

The stability of the relay operation can be improved by using algorithms to detect and compensate the distorted current of the saturated CT's $[50,51]$. Alternatively, the solution used in several commercial available differential relays can also be applied, which consists in blocking the relay when the CT saturation is detected [48]. Another viable solution is the use of optical CT's that eliminate the errors commonly associated with the conventional magnetic CT's [52].

Other experimental and simulation tests carried out for different inrush and fault conditions lead to similar conclusions to the ones presented before. Additionally, identical results were obtained when different sampling frequencies were used (1 kHz to $10 \mathrm{kHz})$. 

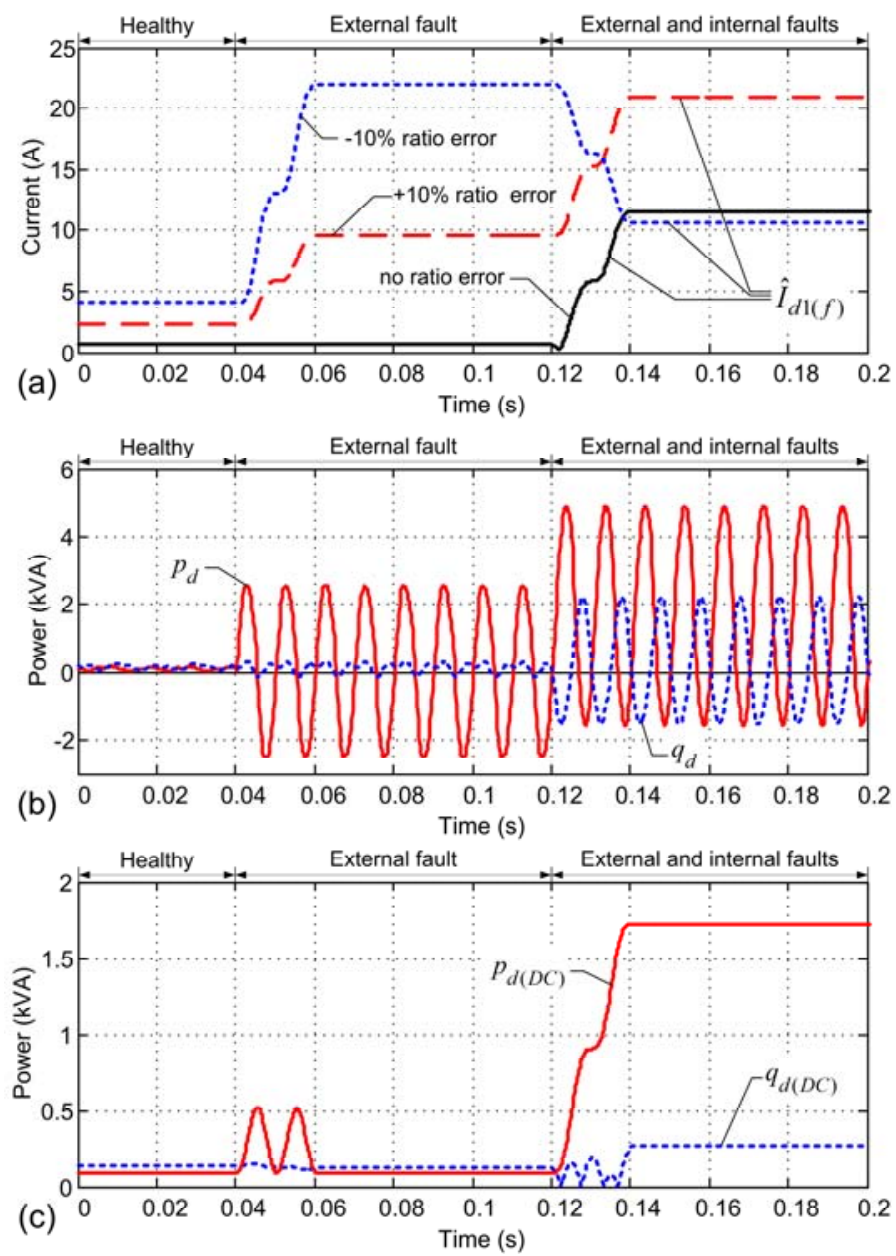

Fig. 6. External fault followed by an internal low-level turn-to-turn fault (unsaturated CT's). (a)

Fundamental component of the differential current $i_{d 1}$ for the cases of $0 \%,+10 \%$ and $-10 \%$ ratio errors; (b) evolution of $q_{d}$ and $p_{d} ;(\mathrm{c})$ evolution of $q_{d(D C)}$ and $p_{d(D C)}$. 

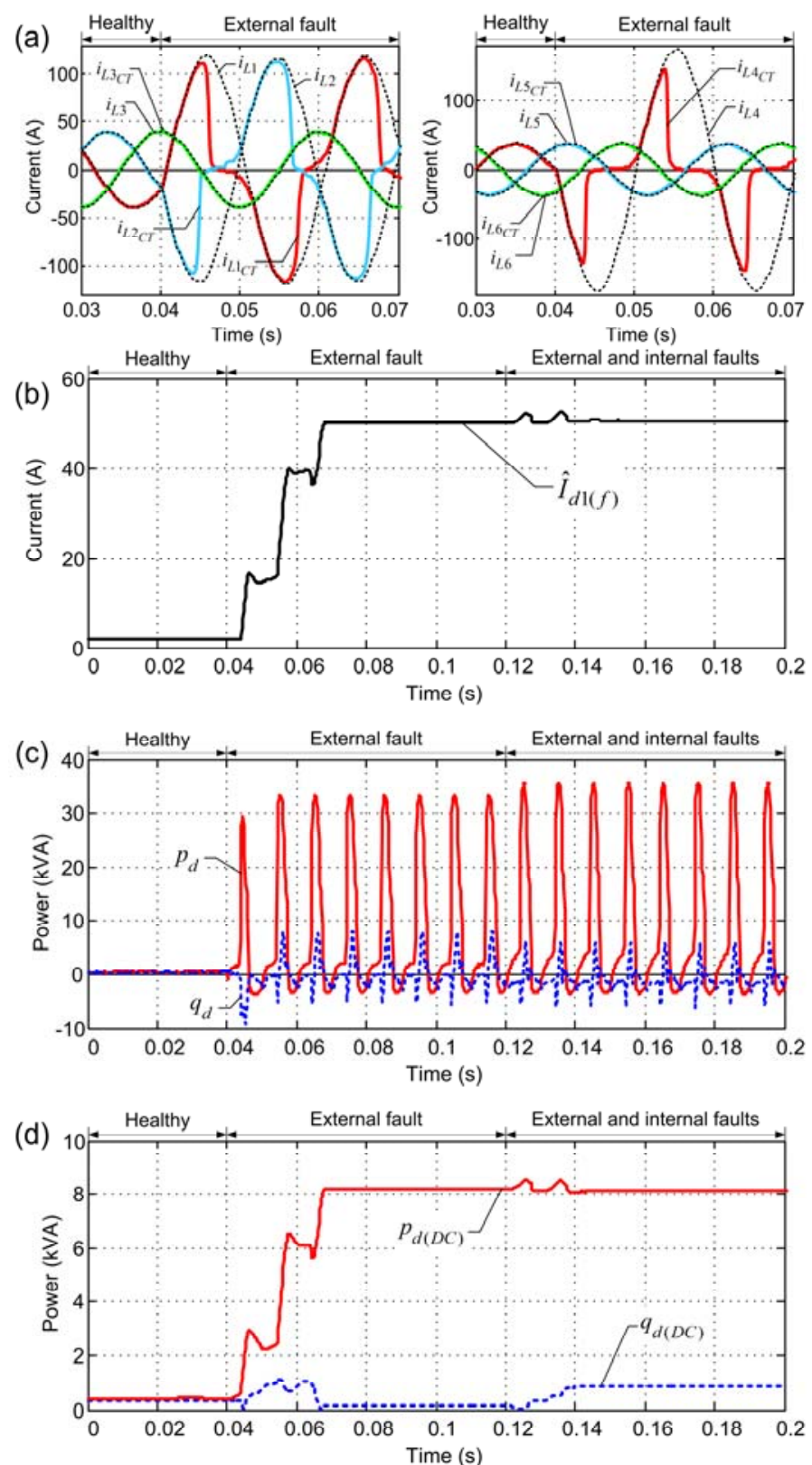

Fig. 7. External fault followed by an internal low-level turn-to-turn fault (saturated CT's and 0\% ratio error). (a) Primary- (dashed) and secondary-side (solid) current waveforms in the CT's (all values referred to the primary-side); (b) fundamental component of the differential current $i_{d 1}$; (c) evolution of $q_{d}$ and $p_{d}$; (d) evolution of $q_{d(D C)}$ and $p_{d(D C)}$.

\section{Conclusions}

This paper presents a novel approach for the differential protection of power transformers. The method is based on the application of the differential Park's power components: the proposed restraining signal, $q_{d(D C)} / p_{d(D C)}$, ensures a robust performance under inrush currents, while the operating signal, $p_{d(D C)}$, provides high sensitivity for the 
detection of internal faults, even in the presence of external ones.

The operating and restraint signals are obtained by using a sliding-window arithmetic average of the differential power components, which has a reduced computational complexity. The computation of the harmonic components of the differential currents is not required and the DFT inherent limitations are overcome.

The restraint signal does not depend on the $2^{\text {nd }}$ harmonic of the differential currents, allowing for an efficient fault/inrush discrimination, and thus inhibiting false relay operations. Additionally, the error introduced by the current mismatch due to the tapchanger is minimized, and increased sensitivity is obtained in the differential protection system.

Experimental and simulated results were presented, which demonstrate that the proposed strategy successfully differentiates between magnetizing inrush and fault conditions. The differential protection sensitivity is even high when low-level internal fault occurs during unit energization process.

The proposed method can be implemented as a stand-alone differential protection scheme or can be used as an improvement of existing protection systems.

Further work is currently in progress, concerning the refinement of the proposed protection technique, with the aim of dealing with transient overvoltages, current transformers severe saturation, sympathetic and recovery inrush currents, or even, the surrounding presence of power electronics equipment.

\section{Acknowledgement}

This work was supported in part by the Portuguese Foundation for Science and Technology (FCT) under Project N SFRH/PROTEC/49261/2008. 


\section{References}

[1] B. Sparling, Managing and extending the life of transformers, Electr. Today (2000).

[2] M. Wang, A.J. Vandermaar, K.D. Srivastava, Review of condition assessment of power transformers in service, IEEE Electr. Insul. Mag. 18 (6) (2002) 12-25.

[3] Z. Wang, Artificial intelligence applications in the diagnosis of power transformer incipient faults, Ph. D. thesis, Faculty of the Virginia Polytechnic Institute and State University, 2000.

[4] C.D. Hayward, Prolonged inrush currents with parallel transformers affect differential relaying, AIEE Trans. 60 (12) (1941) 1096-1101.

[5] L.F. Blume, G. Camilli, S.B. Farnham, H.A. Peterson, Transformer magnetizing inrush currents and influence on system operation, AIEE Trans. 63 (6) (1944) 366-375.

[6] L.F. Kennedy, C.D. Hayward, Harmonic-current-restrained relays for differential protection, AIEE Trans. 57 (5) (1938) 262-266.

[7] M. Thompson, J.R. Closson, Using I $\mathrm{I}_{\mathrm{OP}}$ characteristics to troubleshoot transformer differential relay misoperation, in: Proc. International Electrical Testing Association Technical Conf., 2001.

[8] F. Mekic, R. Girgis, Z. Gajic, E. teNyenhuis, Power transformer characteristics and their effect on protective relays, in: Proc. 33rd Western Protective Relay Conf., 2006.

[9] R.S. Girgis, E.G. teNyenhuis, Characteristics of inrush current of present designs of power transformers, in: Power Engineering Society General Meeting, 2007.

[10] B. Kasztenny, A. Kulidjian, An improved transformer inrush restraint algorithm increases security while maintaining fault response performance, in: Proc. 53rd Annual Conf. for Protective Relay Engineers, 2000.

[11] O.A.S. Youssef, A wavelet-based technique for discrimination between faults and magnetizing inrush currents in transformers, IEEE Trans. Power Deliv. 18 (1) (2003) 170-176.

[12] A. Wiszniewski, W. Rebizanta, L. Schiel, New algorithms for power transformer inter-turn fault protection, Electr. Power Syst. Res. 79 (10) (2009) 1454-1461.

[13] Z. Gajic, I. Brncic, B. Hillström, F. Mekic, I. Ivankovic, Sensitive turn-to-turn fault protection for power transformers, in: Proc. 32th Annual Western Protective Relay Conf., 2005.

[14] S. Andersson, Transformer differential protection, U.S. Patent No 3337772, 1967. 
[15] R. Patterson, W. McCannon, G. Kobet, A consideration of inrush restraint methods in transformer differential relays, in: Proc. 54th Annual Georgia Tech Protective Relaying Conf., 2000.

[16] A. Guzman-Casillas, S. Zocholl, G. Benmouyal, H.J. Altuve, System for power transformer differential protection, U.S. Patent No 6356421, 2002.

[17] A. Kulidjian, B. Kasztenny, Magnetizing inrush restraint method and relay for protection of power transformers, U.S. Patent No 6483680, 2002.

[18] J.A. Sykes, Protection of transformers, U.S. Patent No 3754163, 1973.

[19] A.G. Phadke, J S. Thorp, A new computer-based flux-restrained current-differential relay for power transformer protection, IEEE Trans. Power App. Syst. 102 (11) (1983) 3624-3629.

[20] K. Inagaki, M. Higaki, Y. Matsui, K. Kurita, M. Suzuki, K. Yoshida, T. Maeda, Digital protection method for power transformers based on an equivalent circuit composed of inverse inductance, IEEE Trans. Power Deliv. 3 (4) (1998) 1501-1510.

[21] T.S. Sidhu, H.S. Gill, M.S. Sachdev, A power transformer protection technique with stability during current transformer saturation and ratio-mismatch conditions, IEEE Trans. Power Deliv. 14 (3) (1999) 798-804.

[22] G. Baoming, A.T. Almeida, Z. Qionglin, W. Xiangheng, An equivalent instantaneous inductance-based technique for discrimination between inrush current and internal faults in power transformers, IEEE Trans. Power Deliv. 20 (4) (2005) 2473-2482.

[23] K. Yabe, Power differential method for discrimination between fault and magnetizing inrush current in transformers, IEEE Trans. Power Deliv. 12 (3) (1997) 1109-1118.

[24] M. Guerreiro, V.F. Pires, A transformer differential relay based on a multiple Park transformation, in: Proc. Int. Conf. Power Engineering, Energy and Electrical Drives, 2007.

[25] G. Díaz, P. Arboleya, J. Gómez-Aleixandre, N. Abajo, An algorithm using a shape-based approach in Park's plane for transformer differential relaying on the basis of time-dependent symmetrical components, Electr. Power Syst. Res. 73 (3) (2005) 295-303.

[26] S. Ala, M. Tripathy, A.K. Singh, Identification of internal faults in power transformer using symmetrical components and Park's plots, in: Proc. Int. Conf. Power Systems, 2009. 
[27] L.M.R Oliveira, A.J.M Cardoso, Power transformers behavior under the occurrence of inrush currents and turn-to-turn winding insulation faults, in: Proc. Int. Conf. Electrical Machines, 2010.

[28] H.A. Darwish, M. Lehtonen, Current differential relay with a power-current spectrum blocking for transformer protection, in: Proc. IEEE Bucharest PowerTech Conf., 2009.

[29] J. Ma, Z. Wang, Q. Yang, Y. Liu, A two terminal network-based method for discrimination between internal faults and inrush currents, IEEE Trans. Power Deliv. 25 (3) (2010) 1599-1605.

[30] A. Hooshyar, S. Afsharnia, M. Sanaye-Pasand, B.M. Ebrahimi, A new algorithm to identify magnetizing inrush conditions based on instantaneous frequency of differential power signal, IEEE Trans. Power Deliv. 25 (4) (2010) 2223-2233.

[31] M. Tripathy, R.P. Maheshwari, H.K. Verma, Improved transformer protection using probabilistic neural network and power differential method, Int. Journal of Engineering, Science and Technology 2 (3) (2010) 29-44.

[32] G.D. Rockefeller, Fault protection with a digital computer, IEEE Trans. Power App. Syst. 88 (4) (1969) 438-464.

[33] X. Lin, P. Liu, O.P. Malik, Studies for identification of the inrush based on improved correlation algorithm, IEEE Trans. Power Deliv. 17 (4) (2002) 901-907.

[34] S.B. Wilkinson, Transformer differential relay, U.S. Patent No 5627712, 1997.

[35] J.Faiz, S. Lotfi-Fard, A novel wavelet-based algorithm for discrimination of internal faults from magnetizing inrush currents in power transformers, IEEE Trans. Power Deliv. 21 (4) (2006) 1989-1996.

[36] H. Zhang, P. Liu, O.P. Malik, A new scheme for inrush identification in transformer protection, Electr. Power Syst. Res., 63 (2) (2002) 81-86.

[37] H. Monsef, S. Lotfifard, Internal fault current identification based on wavelet transform in power transformers, Electr. Power Syst. Res., 77 (12) (2007) 1637-1645.

[38] F. Zhalefar, M. Sanaye-Pasand, A new fuzzy-logic-based extended blocking scheme for differential protection of power transformers, Electr. Power Compon. Syst. 38 (6) (2010) 675694.

[39] P. Bastard, H. Regal, Differential protection device of a power transformer, U.S. Patent No 
$5784233,1998$.

[40] M. Tripathy, R.P. Maheshwari, H.K. Verma, Advances in transformer protection: a review, Electr. Power Compon. Syst. 33 (11) (2005) 1203-1209.

[41] A. Ferrero, G. Superti-Furga, A new approach to the definition of power components in threephase systems under nonsinusoidal conditions, IEEE Trans. Instrum. Meas. 40 (3) (1991) 568577.

[42] L.M.R. Oliveira, A.J.M. Cardoso, A permeance-based transformer model and its application to winding interturn arcing fault studies, IEEE Trans. Power Deliv. 25 (3) (2010) 1589-1598.

[43] L. Lawhead, R. Hamilton, J. Horak, Three phase transformer winding configurations and differential relay compensation, in: Proc. 60th Annual Georgia Tech Protective Relay Conf., 2006.

[44] L.M.R. Oliveira, A.J.M. Cardoso, S.M.A. Cruz, Power transformers winding fault diagnosis by the on-load exciting current Extended Park's Vector Approach, Electr. Power Syst. Res. 81 (6) (2011) 1206-1214.

[45] M. Drif, A.J.M. Cardoso, On-line fault diagnostics in operating three-phase induction motors by the active and reactive power media, in: Proc. Int. Conf. Electrical Machines, 2008.

[46] M. Drif, A.J.M. Cardoso, The use of the instantaneous-reactive-power signature analysis for rotor-cage-fault diagnostics in three-phase induction motors, IEEE Trans. Industrial Electronics 56 (11) (2009) 4606-4614.

[47] A.Y. Ahmed, S.I. Al-Mously, Sensitivity improvement of the digital differential relay for internal ground fault protection in the power transformer with tap changer, in: Proc. IEEE Porto PowerTech Conf., 2001.

[48] G. Rockefeller, J. Boyle, L. Lawhead, J. Horak, Transformer protection application guide, Basler Electric Company, 2007.

[49] N. Rajakovic, A. Semlyen, Investigation of the inrush phenomenon, a quasi-stationary approach in the harmonic domain, IEEE Trans. Power Deliv. 4 (4) (1989) 2114-2120.

[50] N. Villamagna, P.A. Crossley, A CT saturation detection algorithm using symmetrical components for current differential protection, IEEE Trans. Power Deliv. 21 (1) (2006) 38-45. 
[51] F.B. Ajaei, M. Sanaye-Pasand, M. Davarpanah, A. Rezaei-Zare, R. Iravani, Compensation of the current-transformer saturation effects for digital relays, IEEE Trans. Power Deliv. 26 (4) (2011) $2531-2540$

[52] J. Horak, J. Hrabliuk, Current transformer errors and transformer inrush as measured by magnetic, optical and other unconventional CTs, Basler Electric Company, www.basler.com. 